\title{
Telomere Length in Renal Cell Carcinoma: The Jekyll and Hyde Biomarker of Ageing of the Kidney
}

This article was published in the following Dove Press journal: Cancer Management and Research

\section{Mariana Morais ${ }^{1,2, *}$ \\ Francisca Dias $\mathbb{D}^{1,3, *}$ \\ Ana Luísa Teixeira $\mathbb{D}^{\prime}$ \\ Rui Medeiros (1D) ${ }^{1-5}$}

'Molecular Oncology and Viral Pathology Group, IPO-Porto Research Center (ClIPOP), Portuguese Oncology Institute of Porto (IPO-Porto), Porto 4200-072, Portugal; ${ }^{2}$ Research Department, LPCCPortuguese League Against Cancer (NRNorte), Porto 4200-I72, Portugal; ${ }^{3}$ ICBAS, Abel Salazar Institute for the Biomedical Sciences, University of Porto, Porto, Portugal; ${ }^{4}$ FMUP, Faculty of Medicine, University of Porto, Porto 4200-319, Portugal; ${ }^{5}$ CEBIMED, Faculty of Health Sciences, Fernando Pessoa University, Porto 4249-004, Portugal

*These authors contributed equally to this work
Correspondence: Ana Luísa Teixeira Molecular Oncology and Viral Pathology Group, IPO-Porto Research Center (ClIPOP), Portuguese Oncology Institute of Porto (IPO-Porto), Rua Dr. António Bernardino de Almeida, Porto 4200-072, Portugal

Tel +35। 225084000 ext: 5410

Fax +35I 22508400 I

Email ana.luisa.teixeira@ipoporto.minsaude.pt

\begin{abstract}
Renal cell carcinoma (RCC) is a heterogeneous group of cancers where the clear cell (ccRCC) is the most common and the most lethal. The absence of accurate diagnostic and follow-up biomarkers along with the time-limited response to therapies may explain the lethality and shows the necessity of new sensitive and specific biomarkers. One of the most studied molecules are the telomeres: specialized ribonucleoprotein structures that keep the structural integrity of the genome. Among other features, telomere length (TL) has been widely studied in several tumor models regarding its biomarker potential, due to the easy detection and quantification. The scope of this review was to analyze all the information about this parameter in RCC. There was some disparity in the results of the studies, since some pointed to an association between short TL and risk or poor outcome of RCC; others between long TL and RCC outcome and some did not find any association. We propose some epidemiological and biological explanations to these differences. The telomeres may play a dual role during RCC carcinogenesis in the early stages, short telomeres may increase RCC risk and in late carcinogenesis, long telomeres seem to be associated with tumor prognosis. However, the controversy of the results along with the lack of specificity are some problems that need to be clarified for the usage of TL as a prognostic biomarker.
\end{abstract}

Keywords: telomere length, biological age, kidney, cancer, biomarker

\section{Introduction}

Kidney cancer accounted for approximately 403 thousand new cases and 175 thousand deaths worldwide in 2018. ${ }^{1}$ There are several types of cancer in this organ but the most common and the most lethal one is renal cell carcinoma (RCC). ${ }^{2}$ Its incidence has been rising along the years and there is a 2:1 male predominance with a peak incidence between 60 and 70 years. ${ }^{3}$ RCC comprises a heterogeneous group of cancers derived from renal tubular epithelial cells with different histopathologic, molecular and clinical characteristics. According to WHO 2016 classification, there are 16 subtypes, but the most common, accounting for $75 \%$ of all cases, and also the most lethal one is clear-cell RCC (ccRCC). ${ }^{4}$ This subtype presents a high tumor cell lipid content and a richly vascularized tumor stroma. However, even within this subtype, there is great heterogeneity and, consequently, great differences in the clinical outcomes of the different patients. ${ }^{3}$

Due to the anatomic location of the kidney, renal masses remain asymptomatic and non-palpable through most of their development. ${ }^{2}$ Consequently, when patients start to present symptoms, the tumor is already in a more advanced stage. 
Additionally, there is a lack of standard screening tests. Despite the fact that the number of incidental detected renal tumors has significantly increased in the last few years, about $30 \%$ of all RCC patients present metastatic disease at the diagnosis. ${ }^{5}$ Even though localized renal neoplasias can be treated using surgery with a curative intent, the only valid options for inoperable or/and metastatic neoplasias are targeted agents and/or immune checkpoint inhibitors, since due to their hypoxic and high vascularity features, these cancers easily become chemoand radioresistant. ${ }^{6,7}$ Nevertheless, these tumors rapidly develop resistance through escaping mechanisms and because of this, inoperable and metastatic ccRCC is still associated with high mortality rates. ${ }^{8,9}$

These current dramatic scenarios, with the absence of accurate diagnostic and follow-up biomarkers, associated with the time-limited response to therapies show the necessity of defining new sensitive and specific biomarkers of diagnosis, prognosis and therapy response monitorization. In the last few years, the telomeres have been studied regarding their biomarker potential.

\section{Telomeres}

Telomeres are specialized ribonucleoprotein structures composed of DNA and bound proteins localized at the end of eukaryotic linear chromosomes that play an essential role in maintaining the structural integrity of the genome. ${ }^{10}$ In humans, telomeres are composed by a noncoding tandem repeat of double-stranded DNA sequence, $5^{\prime}$-(TTAGGG $)_{n}-3^{\prime}$ of variable length followed by a $3^{\prime}$ G-rich single stranded tail of 150-200 nucleotides. ${ }^{11}$

Among other functions, telomeres have two main roles in the cell. Firstly, they differentiate chromosome ends from DNA double-strand breaks and consequently prevent the activation of DNA damage response and avoid genomic instability. ${ }^{12}$ Secondly, they prevent the loss of essential genetic information. Indeed, each division of somatic cells leads to a shortening of telomeres in about 200 nucleotides, since DNA polymerases are unable to completely replicate the ends of linear chromosomes. ${ }^{13}$ When telomeres reach a threshold length cells activate senescence or apoptosis. Nevertheless, a group of cell types which includes the germinal cells, stem cells and cancer cells can keep telomere length through two different telomere maintenance mechanisms (TMMs): telomerase-mediated telomere maintenance and alternative lengthening of telomere (ALT). ${ }^{14}$
These two mechanisms rely deeply on the ability of telomeres to bind to six-subunit protective protein complexes called shelterins. ${ }^{15}$ Each complex is composed by three components that bind in a sequence-specific manner to the tandem repeats: TRF1, TRF2 and POT1; and by three components that bind through protein-protein interactions: RAP1 binds TRF2, TPP1 binds POT1 and TIN2 binds TRF1, TRF2 and TPP1. These complexes bind along the entire length of the telomere and each of its components has specific functions that assure telomere integrity and function. TIN2 is responsible for stabilizing the shelterin complex. ${ }^{16}$ TRF2 prevents an ataxia telangiectasia mutated (ATM) protein-mediated DNA-damage signal, prevents end-to-end fusions and it also stimulates telomere homologous recombination. ${ }^{17,18}$ TRF1 ensures telomere replication and its disruption significantly increases the levels of fragile telomeres and sister-telomere association. ${ }^{19}$ POT1 and TPP1, similarly to TRF2, prevent the ATM-dominated DNA-damage response and telomere fusions. ${ }^{20}$ Moreover, TPP1 is responsible for telomerase recruitment and processivity and for the recruitment of POT $1^{21}$ (Figure 1). Telomerase is a large ribonucleic reverse transcriptase whose function is the addition of TTAGGG repeats at the chromosome ends in order to compensate the progressive telomere attrition. ${ }^{11}$ This cellular enzyme is composed by three subunits: a catalytic subunit with reverse transcriptase activity (hTERT), an essential RNA component (TERC) that serves as template for adding the telomeric repeats and, finally, several components that bind and stabilize TERC, namely dyskerin, reptin, pontin, NOP10, GAR1 and NHP2. ${ }^{16}$ The expression of this complex is tightly regulated in humans. Even though telomerase is widely expressed in the early stages of embryonic development and in pluripotent stem cells, most somatic cells do not show any telomerase activity. Consequently, these cells' telomeres reach a critical length and a damage response is triggered leading to senescence or apoptosis, functioning as a "mitotic clock" against unlimited proliferation. ${ }^{22}$

Besides telomerase, telomere length (TL) can also be regulated by the ALT mechanism. This mechanism is present in around $15 \%$ of immortalized cell lines and human cancer cells. ${ }^{16}$ Despite not being entirely understood, this mechanism is based on homologous recombination dependent exchange or/and homologous recombination dependent synthesis of telomeric DNA. ${ }^{13}$

Even though telomeres were considered to be transcriptionally silent for many years, in 2007, Azzalin et al first described the transcription of several subtelomeric loci located close to the chromosome ends in mammalians. $^{23}$ The telomeric repeat-containing RNA 


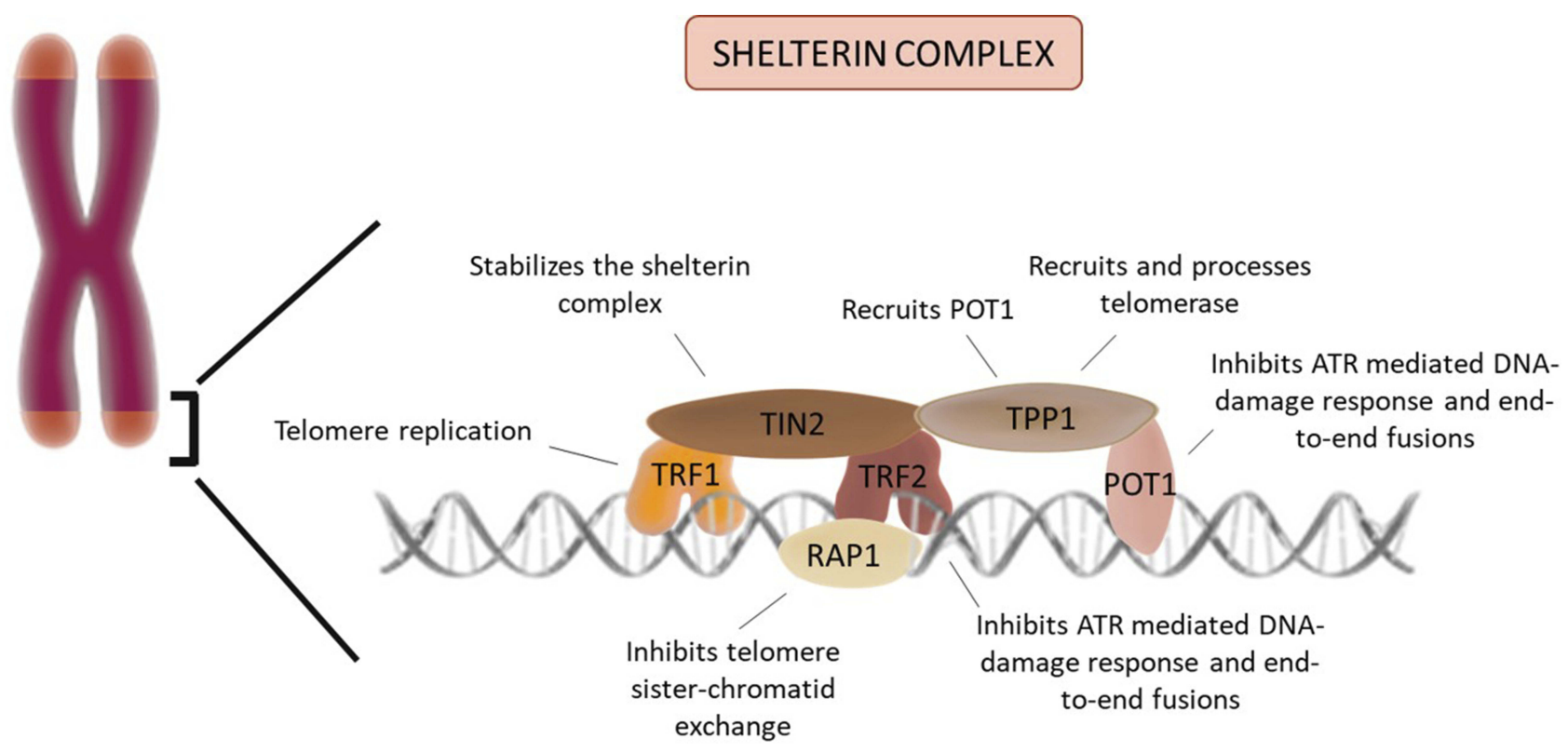

Figure I Telomere and the shelterin complex: Telomeres are stabilized by a protein complex (shelterin). Each component has a specific function essential to the telomere maintenance.

(TERRA) are composed of varying sizes of UUAGG repeat sequences and they have already been detected in yeast, mammals, zebra fish and in microbial pathogens such as Trypanosoma brucei. ${ }^{24,25}$ In mammals, their size ranges from $100 \mathrm{bp}$ to $9 \mathrm{~Kb}$ and they are only transcribed from the C-rich strand. ${ }^{26}$ TERRA participates in the regulation of cell biology having several functions regarding telomeres stability and maintenance, namely in the formation of heterochromatin at telomeres, in the proper capping of chromosome ends and in the regulation of telomere length. ${ }^{27}$ Although the expression of TERRA is highly conserved through evolution, it is important to notice that its dynamics and functions do not seem to be conserved among the different organisms. ${ }^{28}$ In fact, regarding telomere length, TERRA seems to interact with telomerase in different ways. In human and mouse cells, it seems to inhibit telomerase but in budding yeast $S$. cerevisiae and fission yeast $S$. pombe, it was proposed to positively regulate its activity. ${ }^{29,30}$

Telomeres play a vital role in one of the hallmarks of cancer cells: the ability to achieve replicative immortality. ${ }^{31}$ Generally, when telomeres reach a critical short length, cellular senescence or apoptosis is triggered. However, certain cells can escape these events. The upregulation of telomerase, whether it happens through the amplification of the hTERT, duplication or translocation of the locus or even through an overexpression of its promoter (since it is known that it is targeted by numerous oncogenes, tumor suppressors and other transcription factors), is one of these mechanisms. ${ }^{22}$ Other mechanisms are the inactivation of TP53 or Rb or both, initiation of ALT or other key pathways. Consequently, the continued division of cells leads to continued accumulation of mutations. Moreover, abnormal telomeres can cause sticky chromosome ends and like that contribute to chromosomal aneuploidy. ${ }^{10}$ Due to their role and their deregulation in cancer biology, there is the possibility of the usage of this parameter as a potential biomarker in several tumor models, including RCC.

\section{Telomeres as Biomarkers in Cancer}

According to WHO, a biomarker is a biological feature that it is objectively measured and evaluated as an indicator of normal biological or pathological processes or even pharmacological responses to therapeutic interventions. ${ }^{32}$ An ideal biomarker must be easy to measure through minimal invasive methods, easy and not expensive to quantify, specific and sensitive to the disease of interest, able to detect the disease before symptoms and useful in the response to therapy's monitorization. ${ }^{33}$ In the past few years, several prognosis and predictive biomarkers have been suggested in ccRCC, but most of them still need further validation. ${ }^{34}$

The knowledge of the telomeres biology allowed the definition of potential biomarkers in cancer regarding these structures, namely telomerase activity, polymorphisms associated with telomerase or TL. Since telomerase activity is present in most malignant cells but not in normal somatic cells, several researchers have been suggesting the measurement of 
telomerase enzymatic activity or of telomerase gene expression as a potential biomarker. ${ }^{35}$ Studies in prostate, breast, lung, colorectal and kidney cancer have all suggested telomerase activity as a biomarker of poor prognosis. ${ }^{36-41}$ Regarding genetic polymorphisms, one of the most common genes studied is $h T E R T$, which codifies for the catalytic subunit of telomerase. The different variants of genetic polymorphisms in this gene have been associated with differences in TL and with the prognosis of patients in several tumor models, including lung, gastric, breast and kidney cancer. ${ }^{42-45}$ As so, TL is also another widely discussed biomarker since it has been widely associated with innumerous diseases, environmental exposures and phenotypic characteristics. ${ }^{10,40,46}$ There are several methods to determine the TL in tissues, single cells and DNA preparations. ${ }^{47}$

For several years, the golden standard in the determination of the TL was the analysis of the terminal restriction fragment (TelRF) by Southern blot. However, this method required large amounts of DNA, was relatively laborious and could not be used on fixed tissues. ${ }^{48}$ The adaptation of this method to a slot blot assay allows the usage of lower amounts of DNA and can be performed on fixed tissues, but it only mean telomere length and it does not identify telomere length in certain cell types. ${ }^{47}$ On the other hand, Q-FISH is a method that allows the assessment of TL in fixed material and provides single-cell resolution while maintaining the tissue architecture, but it only provides relative telomere measurements while Flow-FISH allows the determination of average TL but can only be used on single-cell suspensions. ${ }^{49}$ A variation of this technique (RNA-FISH) can also be applied in the detection of TERRA, which, as stated before, has been associated with TL regulation. ${ }^{50}$ Quantitative telomere-specific PCR (Q-PCR) is a real-time PCR-based method and, because of that, allows the assessment of large sample sets with low DNA input, but it fails to detect the shortest telomeres and it only provides an average length of the telomeres of the sample. ${ }^{51}$ Single Telomere Length Analysis (STELA) is a recent method that can be used in individual chromosomes to detect their TL and also as the ability to identify extremely short telomeres. However, it is quite laborious and may not detect extremely long telomeres. ${ }^{48}$ Regarding cancer, several studies suggest shorter telomeres as a cancer risk factor but there is still no concordance between authors. ${ }^{47,52}$ Most of the studies report an association between short telomeres and either risk of developing the disease or poor prognosis in breast, colon and prostate. ${ }^{46}$ However, there are contradictory results. For example, there are prospective studies that did not find any association of TL with the most incident cancers. ${ }^{53}$ In addition, there are studies that report significantly longer telomeres in leukocytes of prostate cancer patients, when compared with healthy subjects ${ }^{54}$ Meta-analyses found that these results were highly dependent on the type of study (since they conclusions were different if the studies were prospective or retrospective) and the time of sample collection (before or after diagnosis). ${ }^{55-57}$

The controversy of the results regarding TL and risk or prognosis of cancer is valid for RCC as well, since there are studies reporting either an association with short TL and RCC, long TL and RCC or even no association at all. As so, the scope of this review is to collect and analyze all the information about $\mathrm{TL}$ and its potential as a biomarker in RCC.

\section{Literature Review and Data Collection}

Systematic literature search in PubMed was conducted using the search terms "telomere length", "renal cell carcinoma", "RCC" and "leukocyte telomere length". The articles were selected by relevance of their findings, namely the association of TL and RCC. The literature analysis includes scientific papers published between 1993 and 2018. Obtained scientific papers were manually curated to determine associations between TL and RCC. The criteria of exclusion were as follow: 1) scientific papers that do not directly compare TL in RCC samples with the ones in normal samples, or that do not directly correlate TL with an outcome of the disease; 2) scientific papers that use cell lines instead of human samples; 3) scientific papers that correlate TL with other kidney diseases. Of the 37 papers found, 25 were excluded either because they met the exclusion criteria or because they were review articles, meta-analysis or editorials. For each paper, information was collected concerning the type of sample, TL determination method, type of study, number of samples and main conclusions. The pooled information is synthetized in Table 1.

From the 12 papers included, 9 were case-control studies and 3 were cohort studies. The first studies of TL assessment in RCC are all case-control studies and they all report shorter TL in tumor when compared with the paired normal tissue. ${ }^{58-61}$ Despite the same approach in the study design and the same overall conclusions, they all have specific results that are important to highlight. Holzmann et al have found, in addition to the reduction in telomere size in tumor samples when compared with the normal 
Table I Studies Regarding the Relation Between TL and the Outcomes of RCC

\begin{tabular}{|c|c|c|c|c|c|}
\hline Sample Type & $\begin{array}{l}\text { Method for TL } \\
\text { Determination }\end{array}$ & $\begin{array}{l}\text { Type of } \\
\text { Study }\end{array}$ & Sample Size & Outcome & Reference \\
\hline $\begin{array}{l}\text { Tumor and } \\
\text { matching } \\
\text { normal tissue }\end{array}$ & Southern Blot & Case-Control & 8 cases $/ 2$ controls & Shorter TL observed in tumor DNA & Holzmann et al $1993^{58}$ \\
\hline $\begin{array}{l}\text { Tumor and } \\
\text { matching } \\
\text { normal tissue }\end{array}$ & Southern Blot & Case-Control & $\begin{array}{l}10 \text { cases } / 10 \\
\text { controls }\end{array}$ & $\begin{array}{l}\text { Shorter TL in tumors compared with the } \\
\text { corresponding normal tissue }\end{array}$ & Mehle et al $1994^{59}$ \\
\hline $\begin{array}{l}\text { Tumor and } \\
\text { matching } \\
\text { normal tissue }\end{array}$ & Southern Blot & Case-Control & $\begin{array}{l}59 \text { cases } / 59 \\
\text { controls }\end{array}$ & $\begin{array}{l}\text { Shorter TL in tumors compared with the } \\
\text { corresponding normal tissue }\end{array}$ & Fiedler et al $1996^{60}$ \\
\hline $\begin{array}{l}\text { Tumor and } \\
\text { matching } \\
\text { normal tissue }\end{array}$ & Southern Blot & Case-Control & $\begin{array}{l}60 \text { cases } / 60 \\
\text { controls }\end{array}$ & $\begin{array}{l}72 \% \text { of cases had shorter } \mathrm{TL} \text { in tumor } \\
\text { cells }\end{array}$ & Dahse et al $1999^{61}$ \\
\hline Blood & Q-FISH & Case-Control & $\begin{array}{l}65 \text { cases } / 65 \\
\text { controls }\end{array}$ & $\begin{array}{l}\text { Shorter telomeres in different T-cell } \\
\text { subtypes and in overall PBLs of RCC } \\
\text { cases }\end{array}$ & Shao et al $2007^{62}$ \\
\hline $\begin{array}{l}\text { Tumor tissue, } \\
\text { normal tissue } \\
\text { and blood }\end{array}$ & Real-Time PCR & Cohort & 105 patients & $\begin{array}{l}\text { Tumor tissue's telomeres were shorter } \\
\text { than blood and kidney cortex's } \\
\text { telomeres; longer telomeres in blood is } \\
\text { an independent negative prognostic } \\
\text { factor }\end{array}$ & Svenson et al $2009^{65}$ \\
\hline Blood & Real-Time PCR & Case-Control & $\begin{array}{l}891 \text { cases } / 894 \\
\text { controls }\end{array}$ & No association of TL with risk of RCC & Hofmann et al $201 I^{64}$ \\
\hline Blood & Real-Time PCR & $\begin{array}{l}\text { Prospective } \\
\text { Case-Control }\end{array}$ & $\begin{array}{l}209 \text { cases } / 410 \\
\text { controls }\end{array}$ & No association of $T L$ with risk of RCC & Hofmann et al $2013^{63}$ \\
\hline $\begin{array}{l}\text { Tumor and } \\
\text { normal tissue }\end{array}$ & Southern Blot & Cohort & 100 cases & $\begin{array}{l}\text { Shorter telomere length in tumor } \\
\text { tissues; low-grade tumors had longer TL } \\
\text { than high-grade tumors }\end{array}$ & Pal et al $2015^{66}$ \\
\hline Blood & Southern Blot & Case-Control & $\begin{array}{l}100 \text { cases/ } / 12 \\
\text { controls }\end{array}$ & $\begin{array}{l}\text { No differences in TL between cases and } \\
\text { controls }\end{array}$ & Martino et al $2015^{36}$ \\
\hline Blood & Real-Time PCR & Cohort & 684 cases & $\begin{array}{l}\text { Shorter telomere length was associated } \\
\text { with poorer disease-specific survival }\end{array}$ & Callahan et al $2017^{67}$ \\
\hline Blood & Real-Time PCR & Case-Control & $\begin{array}{l}244 \text { cases } / 53 \\
\text { controls }\end{array}$ & $\begin{array}{l}\text { Shorter telomere length in RCC patients; } \\
\text { telomere length increased with clinical } \\
\text { stage and with tumor size }\end{array}$ & $\begin{array}{l}\text { Morais et al } 2019 \\
\text { (unpublished data) }\end{array}$ \\
\hline
\end{tabular}

Abbreviations: TL, telomere length; RCC, renal cell carcinoma; PBL, peripheral blood lymphocytes.

adjacent ones, the presence of telomeric associations in the chromophobe RCC samples and in oncocytomas in opposition to clear-cell and chromophilic RCC, as well as in normal renal tissue. They suggested that telomeric associations appeared to be related with the histological type of tumors rather than with the grade and size. However, they did not find any differences in the size of telomeres when comparing the tumors with telomeric associations and the ones without. ${ }^{58}$ Regarding the study published by Mehle et al, they also found that all tumors had a reduction in the TelRF length when comparing with the adjacent normal ones, but they also reported an intra-tumoral heterogeneity in several tumor samples. Moreover, some of the tumor samples showed an increase in TelRF volume, which the 
authors proposed that could be related to telomerase activation. ${ }^{59}$ Fiedler et al, for instance, studied not only the TL but also the presence or absence of telomerase activity. ${ }^{60}$ They found that no normal tissue had telomerase activity, in opposition to $93 \%$ of tumor samples analyzed. Interestingly, the four patients who did not show telomerase activity (7\%) did not have metastasis or secondary tumors after a follow-up of two years. Regarding the TL, they found some heterogeneity in their results. The telomerase negative tumors showed a shorter TL comparing with the normal adjacent tissue. In the telomerase positive patients, $60 \%$ had reduced TelRF in tumor areas, $22 \%$ showed no disparity and $18 \%$ showed heterogeneous TelRF length in different tumor areas. This heterogeneity had already been stated by Mehle and Fiedler et al, they hypothesized that it can be due to the activation of telomerase which will consequently stabilize TelRF at different sizes. In concordance with the previous studies, Dahse et al also analyzed, in addition to TL, the presence of telomerase activity. The results are similar to the ones published previously, showing normal tissue's absence of telomerase activity and lack of metastasis or secondary tumors in the patients who were negative for telomerase. Moreover, the researchers reported that $72 \%$ of the RCCs displayed shorter TL in comparison with constitutional tissue, $25 \%$ showed no alterations and two cases had elongated telomeres. ${ }^{61}$

Shao et al also conducted a case-control study, but they were the first to use blood, instead of tissue, and they also used a different TL determination method (Q-FISH). They assessed TL in CD4+ and CD8 $+\mathrm{T}$ cells as well as in Peripheral Blood Lymphocytes (PBLs) and found out there were no significant differences between them. ${ }^{62}$ In concordance with the previous studies, the results showed that shorter telomeres were associated with a higher risk for RCC. This risk was more evident in males than in females and in younger patients rather than the older ones. ${ }^{62}$

In 2015, Martino et al conducted a case-control study, using a southern blot methodology and they did not find any association between TL and RCC risk. ${ }^{36}$ Hoffman et al also conducted two case-control studies, one of them prospective. $^{63}$ In both studies, no differences between cases and controls' TL were found, as well as no associations between TL and tumor stage. ${ }^{63,64}$ Interestingly, these two studies are the ones which display the biggest sample size of all the case-control studies.

Regarding the cohort studies, they all reported an association between shorter telomeres and RCC. Moreover,
Svenson et al compared two sample types: blood and tissue, analyzing the tumor tissue and the corresponding normal cortex tissue along with samples of blood of 105 patients, using for the first-time Real-Time PCR technology to access TL in RCC. Interestingly, they found that tumors had significantly shorter telomeres compared with kidney cortex and blood cells. ${ }^{65}$ Moreover, they found that kidney cortex telomeres were significantly longer when compared with LTL. In addition, they show that RCC patients with the longest LTL had a poorer outcome, no capsule involvement of the tumor and nuclear grade of 1 to 3, verifying long blood relative TL as an independent negative prognostic factor. Pal et al, using a cohort of a hundred patients of RCC found that RCC tissues were significantly shorter than the adjacent normal parenchyma and there was a correlation between TL in different grades of ccRCC: low-grade tumors had significantly longer telomeres. Regarding telomerase, they found that the activity levels of this enzyme were higher in tumor tissues and that high levels were correlated with high grades and stage one and two ccRCC. ${ }^{66}$ Finally, Callahan et al designed a populationbased case-control study using blood samples and RealTime PCR method and found that shorter LTL was significantly associated with poorer disease-specific survival. ${ }^{67}$

To the best of our knowledge, the study conducted in our laboratory, currently submitted for publication, is the most recent one. It was a case-control study, using blood cells, where we found a significative association between shorter telomeres and risk of RCC. Moreover, we found that LTL was longer in T3/T4 patients and in patients with tumors larger than $7 \mathrm{~cm}$, suggesting LTL as a potential prognostic biomarker (Morais et al; unpublished data; 2019).

\section{Discussion}

The potential of TL as a biomarker has been widely assessed by numerous scientists in several age-related diseases. In fact, shorter telomeres have been suggested as risk factors for insulin resistance, overt diabetes mellitus, cardiovascular disease or neurological disorders such as Alzheimer's disease. ${ }^{68,69}$ TL has been associated with some renal dysfunctions. In fact, studies show that TL contribute to renal senescence, impaired potassium clearance, glomerular senescence, renal cysts, fibrosis, glomerulosclerosis and RCC. ${ }^{70}$ In general, short telomeres have been associated with an increased renal injury and decreased recovery. ${ }^{71}$ TL has also been associated with Chronic Kidney Disease (CKD). A systematic review conducted by Ameh O. et al postulated a double role of TL in 
CKD: shortening TL is associated with CKD prevalence and declining kidney function, but an offset of this association due to the cellular telomere reparative process in those surviving longer with $\mathrm{CKD} .^{72}$

TL has been extensively studied in several tumor models. ${ }^{73}$ However, the disparity of results in the studies conducted until now makes it difficult to use TL as biomarker, either of diagnosis or of prognosis. Regarding RCC, there are 12 papers that study the association between TL and this type of cancer. Among them, the results are not concordant, since some point to an association between short TL and either risk of RCC development and poor outcome of the disease; some do not find any association, and some show an association between long TL and RCC outcome of the disease. However, there may be some epidemiological and biological explanations regarding these differences.

Firstly, it is important to notice that the study design and execution are highly variable among the studies. The different sample types, the different techniques used, the fact that some studies are cohorts and other are case-controls, or even the sample size may have influence in the different results. Regarding sample types, Svenson et al indeed proved that the TL depended on the type of sample, showing that telomeres were longer in blood cells than in tumor tissues' ${ }^{65}$ This may be explained by the fact that in blood we find not only tumoral but also genomic DNA. As so, it would be perhaps important to isolate tumoral DNA and only then assess the TL, in order to reduce the variability of results. The different techniques also may influence the results; even though southern blot was, for many years, the golden standard technique, qPCR is more sensitive, less time consuming and needs much less DNA amount. However, it does not detect the shortest telomeres and it only gives an average length of the telomeres of the sample. ${ }^{48}$ But the main influencing factor may be the different types of study design. The fact that in case-control and some of the cohort studies the biological samples were collected after diagnosis and/or treatment initiation may influence the results. Moreover, there may be several confounding variables such as age, demographic and individual factors and results obtained should always be adjusted to these variables. ${ }^{52}$

Nevertheless, there are possible biological explanations that integrate these apparent conflicting results. In the early steps of carcinogenesis, telomeres seem to have a preponderant role in genomic instability. The most common type of genomic instability shows ring-shaped or dicentric chromosomes that fail to undergo normal chromatid separation at anaphase and that instead form chromatin bridges that may break because of the tension forces of the mitotic spindles: the chromosomal breakage-fusion-bridge (BFB) ${ }^{47}$ Interestingly, most tumors with BFB instability present critical telomere shortening. The combination of this instability due to critically short telomeres and of disruptions in cell cycle checkpoints makes it possible for cells to avoid apoptosis. ${ }^{74}$ This may explain why several studies show that tumor tissues display shorter telomeres than the adjacent normal ones or why cancer patients have shorter telomeres than controls. However, there seems to be a reactivation of telomerase by tumor cells in order to prolong neoplastic growth and facilitate tumor progression in later stages of carcinogenesis. More than $85 \%$ of cancers show telomerase activity, suggesting that this enzyme stimulates tumorigenesis by restoring telomere function and enabling tumor cells to achieve immortality. Moreover, even when there is no detectable telomerase activity, telomere's function can be achieved through ALT mechanism. ${ }^{75}$ This would explain the results that show longer telomeres as an independent prognostic factor, the results that state that high-grade tumors, higher clinical stage and with a bigger size show longer telomeres (Figure 2).

The easy detection and quantification of TL, despite the sample type, is the main advantage of this potential biomarker. Nevertheless, it is important to understand that currently there is no cut off for TL that distinguishes short telomeres from long telomeres. On the opposite, these terms are always a comparison between the TL of different groups of individuals. Consequently, the TL of "short telomeres" in one study may not be the same that another study. This is a limitation that needs to be addressed in the near future.

Regarding TL application in clinical practice, the lack of specificity and the controversy of results are main problems that need to be clarified. TL seems to be altered not only in RCC, or even in cancer but also in several agerelated diseases. Moreover, TL highly depends on genetic and environmental factors. Dalgård et al showed that women have telomeres significantly longer than men. ${ }^{76}$ Also, some polymorphisms in hTERT and other specific enzymes related to TL maintenance influence the length of telomeres. Additionally, Alexandrov et al showed that smokers have telomeres significantly shorter than nonsmokers and even ex-smokers. ${ }^{77}$ This compromises the application of TL as biomarker of RCC, and cancer in general, since it can vary not only due to this disease but also because of these factors.

Moreover, the conflicting results found in the studies analyzed in this review can compromise the clinical usage of TL as $\mathrm{RCC}$ biomarker. Even though there seems to be a dual role of 
EARLY PHASE
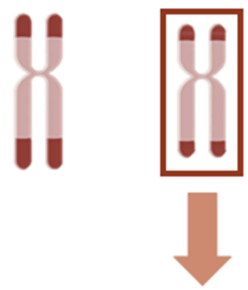

DISRUPTION OF CYCLE CHECKPOINTS
MORE GENOMIC INSTABILITY

(BFB instability)
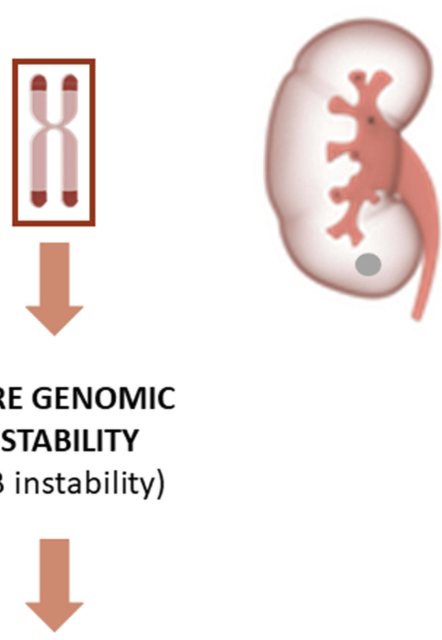

INCREASED RCC RISK
LATE PHASE

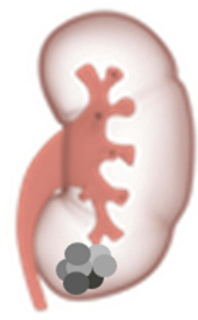

PROLONG NEOPLASTIC GROWTH AND

FACILITATE TUMOR PROGRESSION

WORSE PROGNOSIS

Figure 2 The role of Telomere length in the different steps of carcinogenesis in RCC. In the early stages, short telomeres will increase genomic instability and increase RCC risk; in late carcinogenesis, long telomeres will ease tumor prognosis and worse the prognosis.

telomeres depending on the stage of carcinogenesis that can explain the results, there is still need of studies to clarify confounding aspects that also induce variability in the results published until now. One of the possible confounding variables may be the usage of whole blood to isolate DNA, leading to the detection not only of tumoral DNA but also of DNA derived from normal samples, which can change the medium length of telomeres in RCC cases. Besides, the use of blood collected after or before diagnosis and the design of the studies can also change the results.

As so, although being very difficult to perform, the ideal way of studying TL would be to have a high cohort of healthy subjects from a very early age and to monitor their TL along the years, until there would be a group of individuals who would have been diagnosed with RCC. As so, it would be possible to understand if those patients had significantly shorter LTL before being diagnosed (allowing the understanding of the potential of LTL as a risk biomarker) or if the shortening was coincident with the diagnosis (meaning it was a consequence of the carcinogenesis process). Additionally, the monitoring of these patients' LTL along with the treatment response would also help to clarify if longer TL is associated with resistance to therapies.

\section{Conclusion}

TL seems to have a double role in RCC carcinogenesis: in the early stages, short telomeres seem to increase
$\mathrm{RCC}$ risk due to a rise in genomic instability and in late carcinogenesis, long telomeres seem to be associated with tumor prognosis. In conclusion, despite the initial expectations for the use of $\mathrm{TL}$ as biomarker in $\mathrm{RCC}$, this is still far from being used in clinical practice and there are several disadvantages, concerning either the conflicting results or the lack of specificity. In order to surpass these disadvantages, more studies are needed. Moreover, TL shall be used integrated in a panel of other biomarkers in order to increase its specificity.

\section{Acknowledgments}

We would like to thank to FCT - Fundação para a Ciência e Tecnologia (Portuguese Foundation for Science and Technology) and Liga Portuguesa Contra o Cancro - Núcleo Regional do Norte - LPCC-NRN (Portuguese League Against Cancer - North Branch).

\section{Funding}

ALT is a post-doctoral fellow from FCT (Portuguese Foundation for Science and Technology) [SFRH/BPD/ 111114/2015]. MM is a recipient of a research scholarship awarded by LPCC-NRN. FD is a recipient of a research fellow from the project NORTE-01-0145-FEDER-000027, supported by Norte Portugal Regional Operational Programme (NORTE 2020), under the PORTUGAL 2020 Partnership Agreement, through the European Regional Development Fund (ERDF). 


\section{Disclosure}

All of the authors declare no potential conflicts of interest.

\section{References}

1. Bray F, Ferlay J, Soerjomataram I, Siegel RL, Torre LA, Jemal A. Global cancer statistics 2018: GLOBOCAN estimates of incidence and mortality worldwide for 36 cancers in 185 countries. CA Cancer J Clin. 2018;68(6):394-424. doi:10.3322/caac.21492

2. Escudier B, Porta C, Schmidinger M, et al. Renal cell carcinoma: ESMO clinical practice guidelines for diagnosis, treatment and follow-up. Ann Oncol. 2016;27(suppl 5):v58-v68. doi:10.1093/ annonc/mdw328

3. Hsieh JJ, Purdue MP, Signoretti S, et al. Renal cell carcinoma. Nat Rev Dis Primers. 2017;3:17009. doi:10.1038/nrdp.2017.9

4. Moch H, Cubilla AL, Humphrey PA, Reuter VE, Ulbright TM. The 2016 WHO classification of tumours of the urinary system and male genital organs-Part a: renal, penile, and testicular tumours. Eur Urol. 2016;70(1):93-105. doi:10.1016/j.eururo.2016.02.029

5. Vermassen T, De Meulenaere A, Van de Walle M, Rottey S. Therapeutic approaches in clear cell and non-clear cell renal cell carcinoma. Acta Clin Belg. 2017;72(1):12-18. doi:10.1080/ 17843286.2016.1193269

6. Ljungberg B, Albiges L, Abu-Ghanem Y, et al. European association of urology guidelines on renal cell carcinoma: the 2019 update. Eur Urol. 2019;75:799-810. doi:10.1016/j.eururo.2019.02.011

7. Audenet F, Yates DR, Cancel-Tassin G, Cussenot O, Roupret M. Genetic pathways involved in carcinogenesis of clear cell renal cell carcinoma: genomics towards personalized medicine. BJU Int 2012;109(12):1864-1870. doi:10.1111/j.1464-410X.2011.10661.x

8. Bedke J, Gauler T, Grunwald V, et al. Systemic therapy in metastatic renal cell carcinoma. World J Urol. 2017;35(2):179-188.

9. Ravaud A, Gross-Goupil M. Overcoming resistance to tyrosine kinase inhibitors in renal cell carcinoma. Cancer Treat Rev. 2012;38 (8):996-1003.

10. Savage SA. Beginning at the ends: telomeres and human disease. F1000Res. 2018; 7

11. Gaspar TB, Sa A, Lopes JM, Sobrinho-Simoes M, Soares P, Vinagre J. Telomere maintenance mechanisms in cancer. Genes. 2018;9:5. doi:10.3390/genes9050241

12. Prescott J, Wentzensen IM, Savage SA, De Vivo I. Epidemiologic evidence for a role of telomere dysfunction in cancer etiology. Mutat Res. 2012;730(1-2):75-84. doi:10.1016/j.mrfmmm.2011.06.009

13. De Vitis M, Berardinelli F, Sgura A. Telomere length maintenance in cancer: at the crossroad between telomerase and alternative lengthening of telomeres (ALT). Int J Mol Sci. 2018;19:2. doi:10.3390/ ijms 19020606

14. Shay JW, Wright WE. Senescence and immortalization: role of telomeres and telomerase. Carcinogenesis. 2005;26(5):867-874. doi:10.1093/carcin/bgh296

15. Xu L, Li S, Stohr BA. The role of telomere biology in cancer. Annu Rev Pathol. 2013;8:49-78. doi:10.1146/annurev-pathol-020712-164030

16. Bernal A, Tusell L. Telomeres: implications for cancer development. Int J Mol Sci. 2018;19:1. doi:10.3390/ijms19010294

17. Celli GB, de Lange T. DNA processing is not required for ATM-mediated telomere damage response after TRF2 deletion. Nat Cell Biol. 2005;7(7):712-718. doi:10.1038/ncb1275

18. Celli GB, Denchi EL, de Lange T. Ku70 stimulates fusion of dysfunctional telomeres yet protects chromosome ends from homologous recombination. Nat Cell Biol. 2006;8(8):885-890. doi:10.1038/ ncb1444

19. Sfeir A, Kosiyatrakul ST, Hockemeyer D, et al. Mammalian telomeres resemble fragile sites and require TRF1 for efficient replication. Cell. 2009;138(1):90-103. doi:10.1016/j.cell.2009.06.021
20. Guo X, Deng Y, Lin Y, et al. Dysfunctional telomeres activate an ATM-ATR-dependent DNA damage response to suppress tumorigenesis. EMBO J. 2007;26(22):4709-4719. doi:10.1038/sj. emboj.7601893

21. Abreu E, Aritonovska E, Reichenbach P, et al. TIN2-tethered TPP1 recruits human telomerase to telomeres in vivo. Mol Cell Biol. 2010;30(12):2971-2982. doi:10.1128/MCB.0024 $0-10$

22. Londono-Vallejo JA. Telomere instability and cancer. Biochimie. 2008;90(1):73-82. doi:10.1016/j.biochi.2007.07.009

23. Azzalin CM, Reichenbach P, Khoriauli L, Giulotto E, Lingner J. Telomeric repeat containing RNA and RNA surveillance factors at mammalian chromosome ends. Science (New York, NY). 2007;318 (5851):798-801. doi:10.1126/science.1147182

24. Oliva-Rico D, Herrera LA. Regulated expression of the lncRNA TERRA and its impact on telomere biology. Mech Ageing Dev. 2017;167:16-23. doi:10.1016/j.mad.2017.09.001

25. Nanavaty V, Sandhu R, Jehi SE, Pandya UM, Li B. Trypanosoma brucei RAP1 maintains telomere and subtelomere integrity by suppressing TERRA and telomeric RNA:DNA hybrids. Nucleic Acids Res. 2017;45(10):5785-5796. doi:10.1093/nar/gkx184

26. Cusanelli E, Chartrand P. Telomeric repeat-containing RNA TERRA: a noncoding RNA connecting telomere biology to genome integrity. Front Genet. 2015;6:143. doi:10.3389/fgene.2015. 00143

27. Wang C, Zhao L, Lu S. Role of TERRA in the regulation of telomere length. Int J Biol Sci. 2015;11(3):316-323. doi:10.7150/ijbs.10528

28. Bettin N, Oss Pegorar C, Cusanelli E. The emerging roles of TERRA in telomere maintenance and genome stability. Cells. 2019;8:3. doi:10.3390/cells 8030246

29. Schoeftner S, Blasco MA. Developmentally regulated transcription of mammalian telomeres by DNA-dependent RNA polymerase II. Nat Cell Biol. 2008;10(2):228-236. doi:10.1038/ncb1685

30. Moravec M, Wischnewski H, Bah A, et al. TERRA promotes telomerase-mediated telomere elongation in schizosaccharomyces pombe. EMBO Rep. 2016;17(7):999-1012. doi:10.15252/ embr.201541708

31. Hanahan D, Weinberg RA. Hallmarks of cancer: the next generation. Cell. 2011;144(5):646-674. doi:10.1016/j.cell.2011.02.013

32. Strimbu K, Tavel JA. What are biomarkers? Curr Opin HIV AIDS. 2010;5(6):463-466. doi:10.1097/COH.0b013e32833ed177

33. Weber JA, Baxter DH, Zhang S, et al. The microRNA spectrum in 12 body fluids. Clin Chem. 2010;56(11):1733-1741. doi:10.1373/ clinchem.2010.147405

34. Ngo TC, Wood CG, Karam JA. Biomarkers of renal cell carcinoma. Urol Oncol. 2014;32(3):243-251. doi:10.1016/j.urolonc.2013.07.011

35. Mabruk MJ, O'Flatharta C. Telomerase: is it the future diagnostic and prognostic tool in human cancer? Expert Rev Mol Diagn. 2005;5 (6):907-916. doi:10.1586/14737159.5.6.907

36. de Martino M, Taus C, Lucca I, et al. Association of human telomerase reverse transcriptase gene polymorphisms, serum levels, and telomere length with renal cell carcinoma risk and pathology. Mol Carcinog. 2016;55(10):1458-1466. doi:10.1002/ mc.v55.10

37. Kulic A, Plavetic ND, Gamulin S, Jakic-Razumovic J, Vrbanec D, Sirotkovic-Skerlev M. Telomerase activity in breast cancer patients: association with poor prognosis and more aggressive phenotype. Med Oncol. 2016;33(3):23. doi:10.1007/s12032-016-0736-x

38. Bautista CV, Felis CP, Espinet JM, Garcia JB, Salas JV. Telomerase activity is a prognostic factor for recurrence and survival in rectal cancer. Dis Colon Rectum. 2007;50(5):611-620. doi:10.1007/s10350006-0820-y

39. Fernandez-Marcelo T, Sanchez-Pernaute A, Pascua I, et al. clinical relevance of telomere status and telomerase activity in colorectal cancer. PLoS One. 2016;11(2):e0149626. doi:10.1371/journal. pone. 0149626 
40. Fernandez-Marcelo T, Gomez A, Pascua I, et al. Telomere length and telomerase activity in non-small cell lung cancer prognosis: clinical usefulness of a specific telomere status. J Exp Clin Cancer Res. 2015;34:78. doi:10.1186/s13046-015-0195-9

41. Glybochko PV, Zezerov EG, Glukhov AI, et al. Telomerase as a tumor marker in diagnosis of prostatic intraepithelial neoplasia and prostate cancer. Prostate. 2014;74(10):1043-1051. doi:10.1002/pros.v74.10

42. Iizuka T, Sawabe M, Takubo K, et al. hTERT promoter polymorphism, $-1327 \mathrm{C}>\mathrm{T}$, is associated with the risk of epithelial cancer. Springerplus. 2013;2(1):249. doi:10.1186/2193-1801-2-249

43. Bayram S, Ulger Y, Sumbul AT, et al. Polymorphisms in human telomerase reverse transcriptase (hTERT) gene and susceptibility to gastric cancer in a Turkish population: hospital-based case-control study. Gene. 2016;585(1):84-92. doi:10.1016/j.gene.2016.03.030

44. Hashemi M, Amininia S, Ebrahimi M, Hashemi SM, Taheri M, Ghavami S. Association between hTERT polymorphisms and the risk of breast cancer in a sample of Southeast Iranian population. BMC Res Notes. 2014;7:895. doi:10.1186/1756-0500-7-895

45. Morais M, Dias F, Resende T, Oliveira J, Maurício J, Teixeira AL. Influence of leukocyte telomere length and hTERT genetic polymorphism in renal cell carcinoma clinical outcome. Cell Physiol Biochem. 2018; ahead of print.

46. Herrmann M, Pusceddu I, Marz W, Herrmann W. Telomere biology and age-related diseases. Clin Chem Lab Med. 2018;56 (8):1210-1222. doi:10.1515/cclm-2017-0870

47. Heaphy CM, Meeker AK. The potential utility of telomere-related markers for cancer diagnosis. J Cell Mol Med. 2011;15 (6):1227-1238. doi:10.1111/jcmm.2011.15.issue-6

48. Svenson U, Roos G. Telomere length as a biological marker in malignancy. Biochim Biophys Acta. 2009;1792(4):317-323. doi:10.1016/j.bbadis.2009.01.017

49. Montpetit AJ, Alhareeri AA, Montpetit M, et al. Telomere length: a review of methods for measurement. Nurs Res. 2014;63 (4):289-299. doi:10.1097/NNR.0000000000000037

50. Deng Z, Wang Z, Xiang C, et al. Formation of telomeric repeat-containing RNA (TERRA) foci in highly proliferating mouse cerebellar neuronal progenitors and medulloblastoma. J Cell Sci. 2012;125(Pt 18):4383-4394. doi:10.1242/jcs.108118

51. Cawthon RM. Telomere measurement by quantitative PCR. Nucleic Acids Res. 2002;30(10):e47. doi:10.1093/nar/30.10.e47

52. Hou L, Zhang X, Gawron AJ, Liu J. Surrogate tissue telomere length and cancer risk: shorter or longer? Cancer Lett. 2012;319 (2):130-135. doi:10.1016/j.canlet.2012.01.028

53. Weischer M, Nordestgaard BG, Cawthon RM, Freiberg JJ, TybjaergHansen A, Bojesen SE. Short telomere length, cancer survival, and cancer risk in 47102 individuals. J Natl Cancer Inst. 2013;105 (7):459-468. doi:10.1093/jnci/djt016

54. Julin B, Shui I, Heaphy CM, et al. Circulating leukocyte telomere length and risk of overall and aggressive prostate cancer. $\mathrm{Br}$ $J$ Cancer. 2015;112(4):769-776. doi:10.1038/bjc.2014.640

55. Zhang C, Chen X, Li L, Zhou Y, Wang C, Hou S. The association between telomere length and cancer prognosis: evidence from a meta-analysis. PLoS One. 2015;10(7):e0133174. doi:10.1371/journal.pone.0133174

56. Xu X, Qu K, Pang Q, Wang Z, Zhou Y, Liu C. Association between telomere length and survival in cancer patients: a meta-analysis and review of literature. Front Med. 2016;10(2):191-203. doi:10.1007/ s11684-016-0450-2

57. Zhang X, Zhao Q, Zhu W, et al. The association of telomere length in peripheral blood cells with cancer risk: a systematic review and meta-analysis of prospective studies. Cancer Epidemiol Biomarkers Prev. 2017;26(9):1381-1390. doi:10.1158/1055-9965.EPI-16-0968

58. Holzmann K, Blin N, Welter C, Zang KD, Seitz G, Henn W. Telomeric associations and loss of telomeric DNA repeats in renal tumors. Genes Chromosomes Cancer. 1993;6(3):178-181. doi:10.1002/(ISSN)1098-2264
59. Mehle C, Ljungberg B, Roos G. Telomere shortening in renal cell carcinoma. Cancer Res. 1994;54(1):236-241.

60. Fiedler W, Dahse R, Schlichter A, et al. Telomerase activity and telomere length in different areas of renal cell carcinoma. Int J Oncol. 1996;9(6):1227-1232. doi:10.3892/ijo.9.6.1227

61. Dahse R, Fiedler W, Junker K, Schlichter A, Schubert J, Claussen U. Telomerase activity and telomere lengths: alterations in renal cell carcinomas. Kidney Int. 1999;56(4):1289-1290. doi:10.1046/j.15231755.1999.00688.x

62. Shao L, Wood CG, Zhang D, et al. Telomere dysfunction in peripheral lymphocytes as a potential predisposition factor for renal cancer. J Urol. 2007;178(4):1492-1496. doi:10.1016/j.juro.2007.05.112

63. Hofmann JN, Lan Q, Cawthon R, et al. A prospective study of leukocyte telomere length and risk of renal cell carcinoma. Cancer Epidemiol Biomarkers Prev. 2013;22(5):997-1000. doi:10.1158/ 1055-9965.EPI-13-0142

64. Hofmann JN, Baccarelli A, Schwartz K, et al. Risk of renal cell carcinoma in relation to blood telomere length in a population-based case-control study. Br J Cancer. 2011;105 (11):1772-1775. doi:10.1038/bjc.2011.444

65. Svenson U, Ljungberg B, Roos G. Telomere length in peripheral blood predicts survival in clear cell renal cell carcinoma. Cancer Res. 2009;69(7):2896-2901. doi:10.1158/0008-5472.CAN-083513

66. Pal D, Sharma U, Khajuria R, Singh SK, Kakkar N, Prasad R. Augmented telomerase activity, reduced telomere length and the presence of alternative lengthening of telomere in renal cell carcinoma: plausible predictive and diagnostic markers. Gene. 2015;562 (2):145-151. doi:10.1016/j.gene.2015.02.079

67. Callahan CL, Schwartz K, Ruterbusch JJ, et al. Leukocyte telomere length and renal cell carcinoma survival in two studies. Br J Cancer. 2017;117(5):752-755. doi:10.1038/bjc.2017.237

68. Kirchner H, Shaheen F, Kalscheuer H, Schmid SM, Oster H, Lehnert H. The telomeric complex and metabolic disease. Genes. 2017;8(7):176. doi:10.3390/genes8070176

69. Fyhrquist F, Silventoinen K, Saijonmaa O, et al. Telomere length and cardiovascular risk in hypertensive patients with left ventricular hypertrophy: the LIFE study. J Hum Hypertens. 2011;25 (12):711-718. doi:10.1038/jhh.2011.57

70. Wills LP, Schnellmann RG. Telomeres and telomerase in renal health. J Am Soc Nephrol. 2011;22(1):39-41. doi:10.1681/ ASN.2010060662

71. Westhoff JH, Schildhorn C, Jacobi C, et al. Telomere shortening reduces regenerative capacity after acute kidney injury. $\mathrm{J} \mathrm{Am}$ Soc Nephrol. 2010;21(2):327-336. doi:10.1681/ASN.2009010 072

72. Ameh OI, Okpechi IG, Dandara C, Kengne AP. Association between telomere length, chronic kidney disease, and renal traits: a systematic review. OMICS. 2017;21(3):143-155. doi:10.1089/ omi.2016.0180

73. Zhang C, Doherty JA, Burgess S, et al. Genetic determinants of telomere length and risk of common cancers: a Mendelian randomization study. Hum Mol Genet. 2015;24(18):5356-5366.

74. Calcagnile O, Gisselsson D. Telomere dysfunction and telomerase activation in cancer - a pathological paradox? Cytogenet Genome Res. 2007;118(2-4):270-276.

75. Hackett JA, Greider CW. Balancing instability: dual roles for telomerase and telomere dysfunction in tumorigenesis. Oncogene. 2002;21(4):619-626.

76. Dalgard C, Benetos A, Verhulst S, et al. Leukocyte telomere length dynamics in women and men: menopause vs age effects. Int J Epidemiol. 2015;44(5):1688-1695.

77. Alexandrov LB, Ju YS, Haase K, et al. Mutational signatures associated with tobacco smoking in human cancer. Science (New York, NY). 2016;354(6312):618-622. 


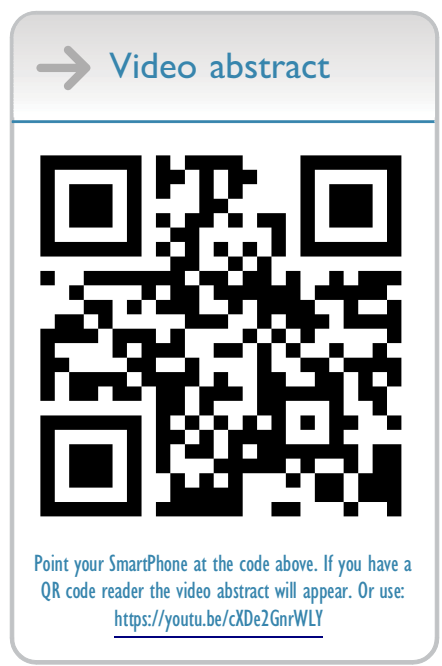

Cancer Management and Research

\section{Publish your work in this journal}

Cancer Management and Research is an international, peer-reviewed open access journal focusing on cancer research and the optimal use of preventative and integrated treatment interventions to achieve improved outcomes, enhanced survival and quality of life for the cancer patient.
The manuscript management system is completely online and includes a very quick and fair peer-review system, which is all easy to use. Visit http://www.dovepress.com/testimonials.php to read real quotes from published authors. 